\title{
Performance Analysis of Interior Beam-column Joint of Buckling Restrained Brace Reinforced Concrete Frame
}

\author{
Jiang ZHU ${ }^{1,2, a}$, Guo-Chang $\mathrm{LI}^{3, \mathrm{~b}^{*}}$ \\ ${ }^{1}$ School of civil engineering of Dalian University of technology, Liaoning, Dalian, china \\ ${ }^{2}$ Institute of architecture and engineering of Shenyang University, Liaoning, Shenyang, china \\ ${ }^{3}$ Shenyang Architectural University, Liaoning, Shenyang, china \\ az-hujiang@163.com, ${ }^{\mathrm{b}}$ Liguochang0604i@sina.com \\ ${ }^{*}$ Corresponding author
}

Keywords: Buckling Restrained Brace, Finite Element Analysis, Moment-rotation Curves, Mechanical Behavior, Joint.

\begin{abstract}
A type of connection was proposed to connect buckling restrained braces in reinforced concrete frames. Performance under Monotonic load of the joint were analyzed by ABAQUS, the development of cracks and deformations is studied, and the ultimate state and the failure mode are determined. In addition, the stress of each part of the joint and the shear force in the joint core are obtained. The study shows that the decrease of the bearing capability and the destruction of the joint under monotonic loading is due to the failure of the concrete in beam. This joints force evenly, power transmission clear, and have good performance.
\end{abstract}

\section{Introduction}

In recent years, buckling restrained brace $(\mathrm{BRB})$ as a new type of energy dissipation component, is gradually applied in seismic design of structures (BRBF). This system has largely been used in the America and Japan. This kind of brace has large initial rigidity, can easily satisfy the deformation requirements specification under small earthquake; In the earthquake, BRB can field under tensile or compression, and can eliminate the brace buckling problems of traditional brace framework, has good energy dissipation capacity, can effectively reduce the overall cost of the project[1-3]. In china, the concrete structure is still dominant, but its seismic performance is poorer than the steel structure, difficult to repair after earthquake. If the BRB for concrete frame is able to greatly improve their seismic performance, which connection node design and construction of BRB with reinforced concrete frame is the key. Therefore, we propose a form of connection joint of BRB with reinforced concrete frame beams, column, analysis and understand the bearing characteristic and failure mode by the finite element analysis is proposed to construct a reasonable measures to provide a reference for the practical application of engineering.

\section{Joint Formation}

The joint is mainly composed of steel plate and welding stud at steel plate, its structure form as shown in Figure 1. Combined with the concrete casting formwork, steel plate embedded in reinforced concrete beams, columns, steel and concrete coordination through studs to achieve, stud number can be determined by calculation.

\section{Finite Element Model}

\section{Joint Model}

A nine-story reinforced concrete buckling-restrained brace frame designed according to [4], With the lower floor, the brace exposure the greater seismic forces, so take interior beam-column-brace joints of the second floor in this BRBF to analysis by finite element. Concrete strength is C50, The 
beam section of the model was $150 \mathrm{~mm} \times 350 \mathrm{~mm}$ and the column cross section was $300 \mathrm{~mm} \times 300$ $\mathrm{mm}$. The model represented a connection part of the frame obtained by terminating the beam and column at it mid-span. Number of studs were calculated based on the axial force of BRB ${ }^{\mathbf{I} 4 \mathbf{I}}$.

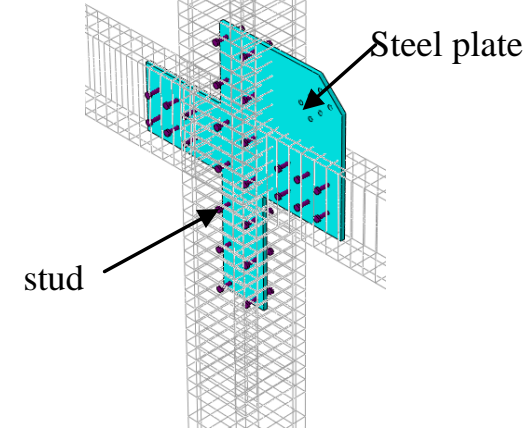

Fig. 1 Details of connection

\section{Material Proprieties}

In this study, the performance of joint was analyzed by ABAQUS. According to the code for design of concrete structures(GB50010-2002) [5], compressive strength of concrete $f_{c}$ and tensile strength of concrete $f_{t r}$ was equal to $23.1 \mathrm{Mpa}, 1.89 \mathrm{Mpa}$ respectively. Longitudinal reinforcement for the beam and columns consisted of deformed bars characterized by an yield strength $f_{y}$ equal to $417 \mathrm{MPa}$. Bar diameters of longitudinal reinforcement were varied from $10 \mathrm{~mm}$ to $14 \mathrm{~mm}$. Mild steel bars of $6 \mathrm{~mm}$ diameter characterized by an yield strength $f_{y}$ equal to $235 \mathrm{MPa}$ were used for transverse reinforcement. Alloy steel of $15 \mathrm{~mm}$ thickness, $13 \mathrm{~mm}$ diameters characterized by an yield strength $f_{y}$ equal to $276 \mathrm{MPa}, 320 \mathrm{Mpa}$ were used for steel plate, stud respectively. In this paper, a damaged plasticity model has been used for the concrete.

\section{Interface Conditions}

The interface between the steel and concrete surfaces was modeled using contact pairs consisting of master (steel) and slave (concrete) surfaces. Hard contact was specified in normal direction. The tangent direction use the bond slip model (HanLinHai,2007)[6]. The coefficient of friction, ${ }^{\mu}$, was initially chosen to be 0.5 between the gusset plate and concrete, but it was chosen to be 0.1 between the stud and concrete.

\section{FE Model Result and Discussion}

the mechanical schematic of the interior beam-column Joint as shown in Figure 2 (a).Joint moment (M) can be calculated according to the following formula:

$$
M=\frac{\left(P_{\text {左 }}+P_{\text {右 }}\right) L}{2}
$$

where $P_{\text {左 }}, P_{\text {右 }}$ is Vertical load to the beam end; $L$ is The total length of the beam; beam, column relative angle $\theta$ can be determined according to figure 2 (b). Calculation of the relative rotation angle according to the distance change between beam edge of 1 point and t column edge of 2 point is determined by the following formula, taking the angle between the two beams and columns mean, that:

$$
\theta=\frac{2 \Delta}{L}
$$




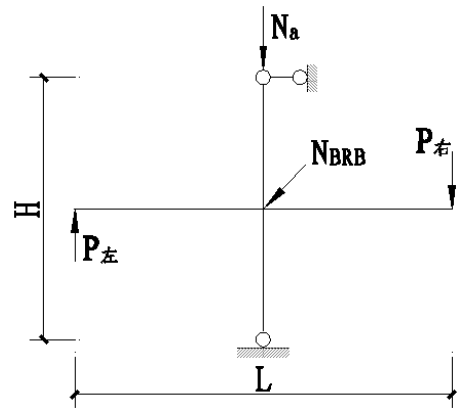

(a)

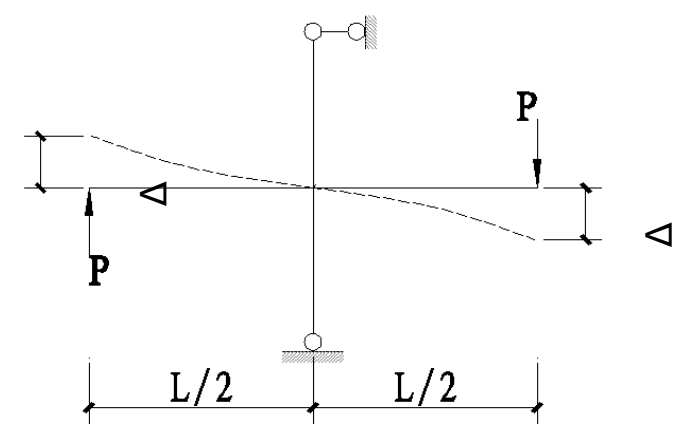

(b)

Fig.2 Boundary and loading conditions

\section{Moment-rotation Curve of Joint under Monotonic Loading and Failure Process}

According to the design results of BRBF, select the axial compression ratio of 0.2 in the joint model. Based on moment-rotation curve $(M-\theta)$ of joint under uniaxial loading analysis mechanism of the composite joints. Figure 3 shows the moment-rotation curve of composite joint that calculated according to formula (1) (2) in the BRB compression and tension respectively. According to the curve, the joint stress process can be roughly divided into three stages: elastic stage (OB), elastic and plastic stage(BC) and failure stage (CD). Point A to the fluctuation is due to concrete cracking significant in the tension zone of the beam and the stud intersection; Point $\mathrm{B}$ for the beam longitudinal reinforcement; Point $\mathrm{C}$ is the maximum capacity of joint corresponding points; Point $\mathrm{D}$ for bearing capacity decreased to $85 \%$ of the ultimate bearing capacity, which corresponds to the failure load $\mathrm{M}_{\mathrm{u}}$.

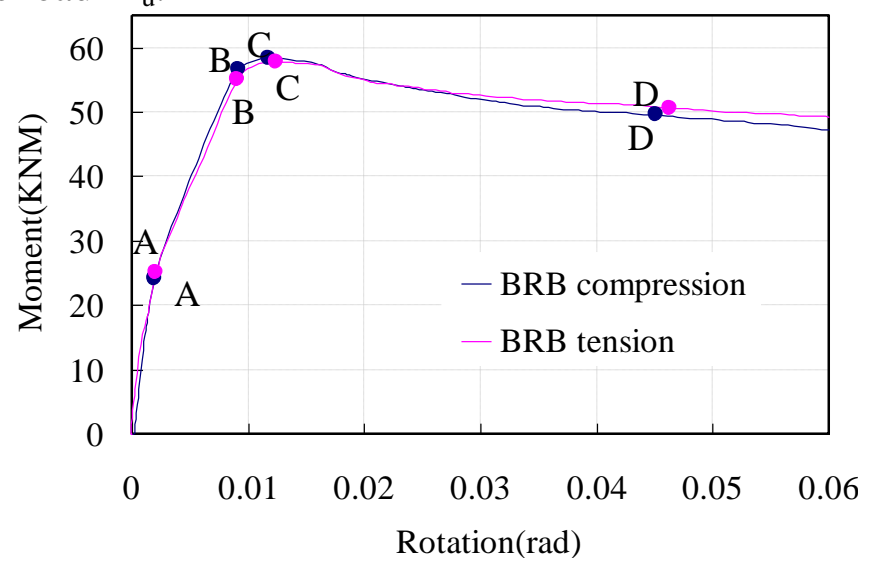

Fig 3 Moment - rotation curves of joint

Moment, angle corresponding to each of the feature points and the corresponding state is shown in Table 1. From figure 3 and table 1 can be seen, although failure process of joint in the two state is consistent but each feature points are different. This is due to structural asymmetry of the combination joint (Fig.1).

Tab. 1 Analysis results for characteristic points

\begin{tabular}{|c|c|c|c|c|}
\hline & $A$ (tension) & $B$ (tension) & $C$ (tension) & $D$ (tension) \\
\hline Moment(KNM) & $24.16(25.16)$ & $56.7(55.09)$ & $58.42(57.8)$ & $49.57(50.69)$ \\
\hline Rotation ( rad) & $0.0019(0.002)$ & $0.0078(0.0091)$ & $0.0111(0.0124)$ & $0.045(0.046)$ \\
\hline Joint status & $\begin{array}{c}\text { Concrete cracking } \\
\text { at tension zone of } \\
\text { beam, column }\end{array}$ & $\begin{array}{c}\text { Yield tensile } \\
\text { reinforcement in } \\
\text { the beam }\end{array}$ & $\begin{array}{c}\text { Concrete crushed } \\
\text { at compression } \\
\text { zone in beam }\end{array}$ \\
\hline
\end{tabular}

\section{Concrete Crack and Failure Analysis}

According to Lubliner et al (1989) [7], cracks occurred primarily in the concrete equivalent 
plastic strain is greater than zero, namely: $\varepsilon_{t}>0$, and the maximum principal plastic strain is positive point. The crack development direction, width and distribution status can be observed in accordance with the minimum plastic strain in ABAQUS. When the value of the minimum principal strain reached the limits of concrete compressive strain $(\varepsilon=0.0033)$, indicating that the concrete crushing at the location. Here, With the joint is subjected to negative moment (BRB compression) as an example, Analysis of the crack and destruction development process under different stress stages of the composite joints, as shown in figure 4. It can be seen from figure 4, Initial crack is vertical cracks appeared mainly in stud location along the steel border with beam,. With the increase of load, crack down to continue development increased range at the same time, when the yield point is reached, the fracture extension to stud at the beam bottom. When the load reaches the limit state, concrete compression zone reaches the maximum compressive stress, concrete failure begins. When Failure, forming a main through crack at right beam and left beam, concrete crushing. in the beam compression zone.

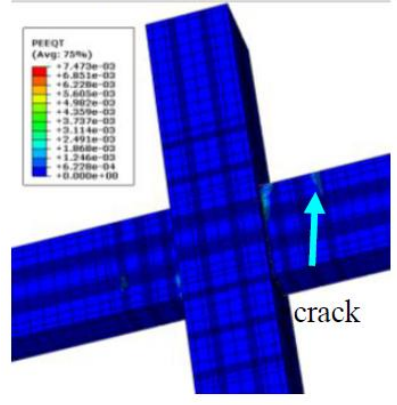

(a) the initial crack (point A)

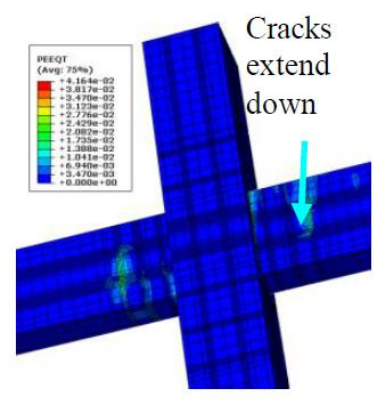

(b) Yield stage (point B)

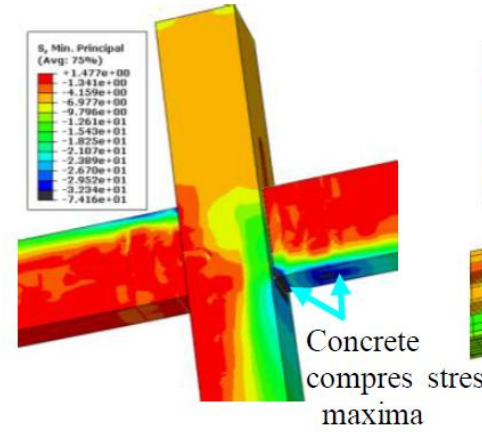

(c) limit stage (point C)

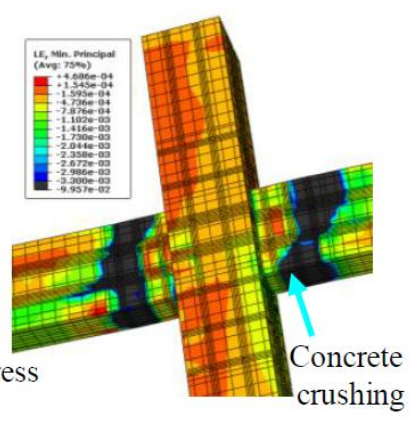

(d) Failure stage ( point D)

Fig.4 crack development and crush in concrete for joint

\section{Reinforcement Stress}
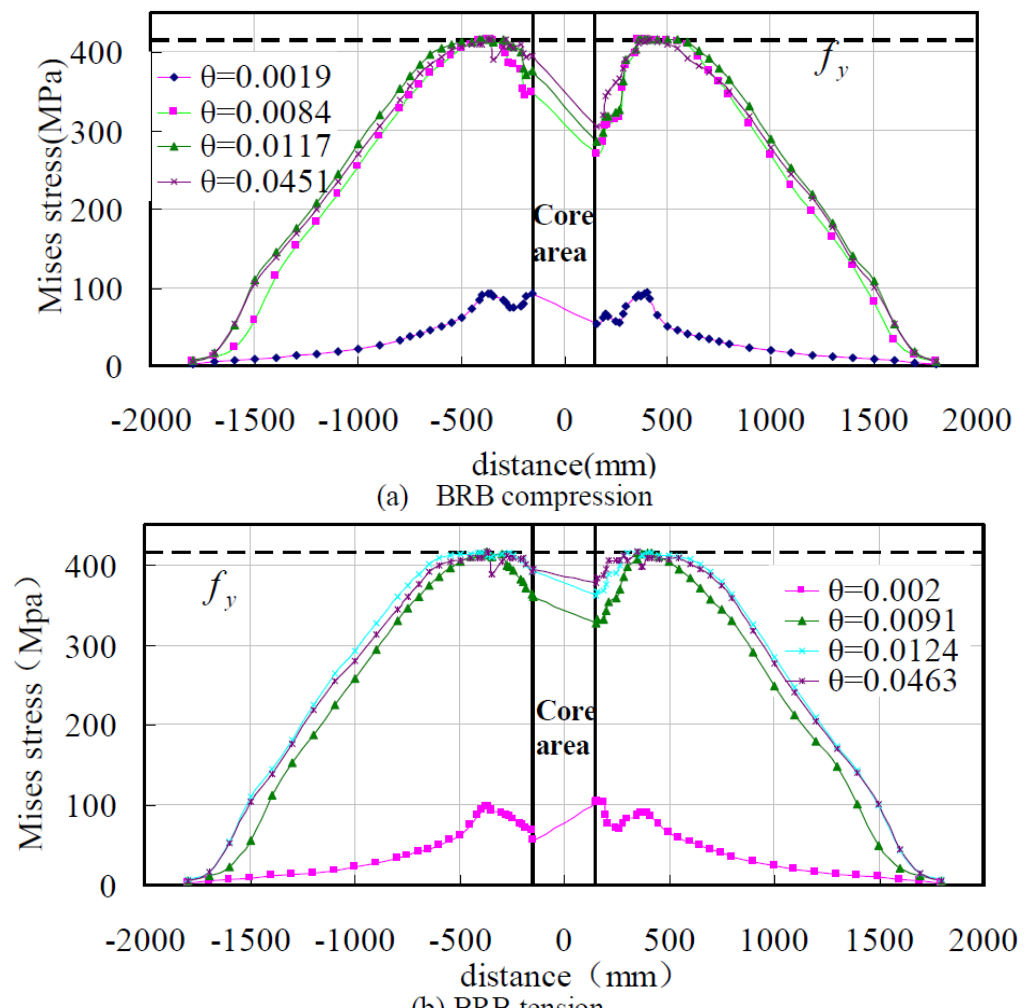

(b) BRB tension

Fig 5 Mises stress distribution of tensile reinforcement in beam

Fig 5(a) shows that the stress change of the tensile reinforcement in beam along the beam length 
when the joint under negative moment (BRB compression). The results can be seen from fig: (1) Reinforced keep elasticity before the node rotation reached $\theta=0.0117$ ( point B) (2) The right beam tensile reinforcement first yield at $200 \mathrm{~mm}$ from the column face(outermost stud position, the location is also the concrete cracking at first) then extended to both sides extend to $300 \mathrm{~mm}$ from column face. Also the left beam tensile reinforcement first yield at $200 \mathrm{~mm}$ from the column face then extended to both sides extend to $220 \mathrm{~mm}$ and $140 \mathrm{~mm}$ from column face; (3) Reinforcement in core area did not yield indicating that the node core area does not undermine, consistent with "strong joint" the design principles; (4) The plastic hinge region in left beam than the right beam and close to the core area, indicating the brace connecting plate is subjected to a part of the internal force.

Fig 5(b) shows that the stress change of the tensile reinforcement in beam along the beam length when the joint under negative moment (BRB compression). The results similar to the results of BRB compression.

\section{Study Analysis}

In this joint form, stud is important to pass force component, BRB force forces are transmitted through the studs in concrete beams so the force of stud play an important role on joint performance. Whether the material yield can use the variable AC YIELD calibration in ABAQUS, if $A C$ YIELD $=0$ materials did not yield, if $A C$ YIELD $>0$ said the material yield. The yield changes of stud in elastic state (point B), ultimate limit state (point C) and damage state (point D) shown in Figure 6 and 7.

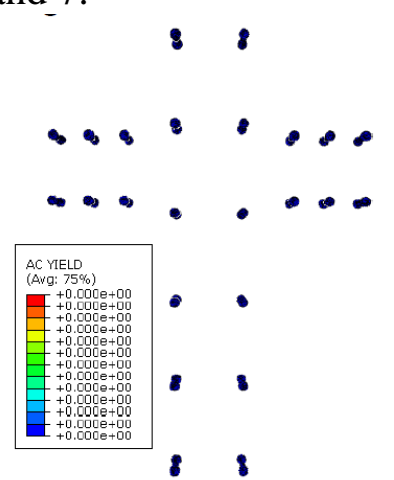

(a) Yield stage (point B)

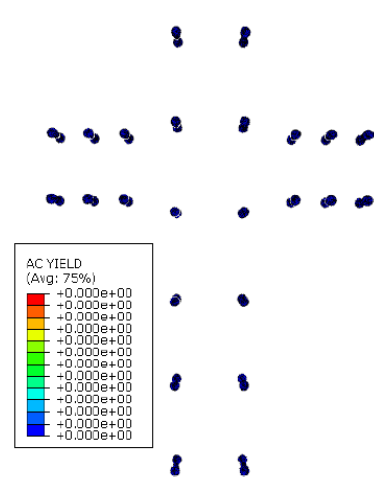

(b) limit stage (point C)

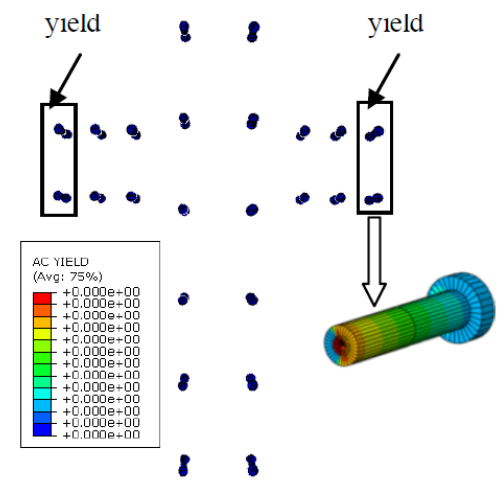

(c) Failure stage (point D)

Fig 6 Yield changes of stud (BRB compression)

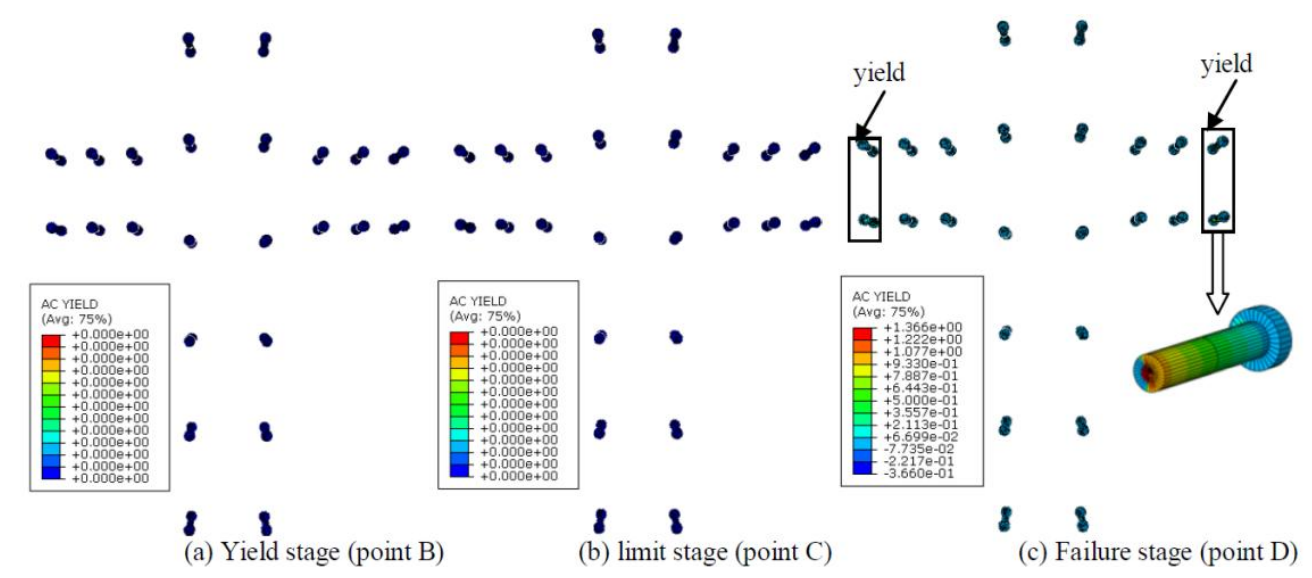

Fig 7 Yield changes of stud (BRB tension)

As can be seen from the results shown:

(1) When the joint into the failure state, the stud bottom that the edge position of the plate in beam began to yield; (2) The stud first yield at Beam tension zone plate edge then with the increase load gradually development to the compression zone and the final all studs yield at the location as 
shown in Figure 16, 17 (b), (c) (Stud yield is only a small portion of the bottom welding with steel plate while other parts of the studs did not yield);(3) Column studs in the whole loading process were not yield indicating that column force is smaller than the beam to meet the "strong column weak beam" design requirements; (4)The stress distribution of each stud is gradually become smaller from the bottom to the top, when reaching the limit state the top of studs were still not reached the yield stress.

\section{Summary}

From the above analysis we can draw some characteristics of interior beam-column joint of BRBF in the failure modes and stress mechanism:

(1) The stress process of joint be divided into elastic stage, elastic and plastic stage and failure stage the three stages and showed good ductility;

(2) Finite element analysis results indicate that the bearing capacity of the joint is higher than the connected components under static load so as to meet the "strong node, the weak components"

(3) The composite joint initial failure occurs in steel plate and reinforced concrete beam junction so meet the seismic design of the "strong column weak beam" principle;

(4) Loading to failure stage, the majority studs in this combination joint remain elastic in addition to individual yield but no destroyed indicating that studs played a good role in the force transmission.

\section{References}

[1] SUN Kuan. Analysis of seismic response on buckling restrained braces reinforced concrete frame core-tube structures[D].Lanzhou University of Technology, 2014. (in Chinese)

[2] ZHOU Yun, TANG Rong. State-of-the-art and State-of-the-practice of Buckling-restrained Brace [J], Journal of Disaster Prevention and Mitigation Engineering, 2012,32(4) : 393-407. (in Chinese)

[3] ZHOU Yun. Structure design and application of buckling-restrained brace[M]. Beijing: China Architecture\&Building Press, 2007.(in Chinese)

[4] ZHU Jiang, LI Guo Chang, MA Chuan Zheng. Analysis and design on performance of Buckling restrained braces reinforced concrete frame structure[J].Building Structures,2012,42(12) : 54-58. (in Chinese)

[5] Code for design of concrete structure(GB50010-2010) [S].2010

[6] Han lin hai. Concrete filled steel tube structure-theory and practice(The second edition) [M]. Beijing: Science press, 2007

[7] Lubliner J, Oliver J, Oller S, Onate E. A plastic-damage model for concrete [J]. International Journal of Solids and Structures, 1989, 25(3): 299-326. 